\title{
Job Club: A Program to Assist Occupational Therapy Students' Transition to Practice
}

\author{
Katrina Liddiard ${ }^{1}$, Rachel Batten ${ }^{1}$, Yuluan Wang ${ }^{2}$, Karen Long ${ }^{1}$, Amy Wallis ${ }^{1}$ and \\ Cary A Brown ${ }^{2, *}$ ib \\ 1 Occupational Therapy, School of Medical and Health Sciences, Edith Cowan University, \\ 270 Joondalup Drive, Joondalup WA 6018, Australia; k.liddiard@ecu.edu.au (K.L.); \\ r.batten@ecu.edu.au (R.B.); k.long@ecu.edu.au (K.L.); a.wallis@ecu.edu.au (A.W.) \\ 2 Occupational Therapy Department, 2-64 Corbett Hall, Faculty of Rehabilitation Medicine, \\ University of Alberta, Edmonton, AB T6E4H4, Canada; yuluan@ualberta.ca \\ * Correspondence: cary.brown@ualberta.ca; Tel.: +1-780-492-9545
}

Received: 2 July 2017; Accepted: 31 August 2017; Published: 4 September 2017

\begin{abstract}
Transition to practice can be identified as the change from the role of student to the role of practitioner. This period of transition is a time of intense professional and personal development. Typically, it can take anywhere between six months to two years before an entry-level therapist feels competent in the workplace. A number of factors affect the transition process, including role uncertainty, inadequate supervision, and an overall lack of confidence in clinical skills. This paper discusses a case example of a Job Club, provided by a Western Australian Occupational Therapy university program. The concept was initially set up to support students through the process of seeking and gaining employment. Over time, the club developed a broader scope based on the needs of attendees. This example illustrates the needs of students for greater support in this important transition, and lays the groundwork for formal research in future.
\end{abstract}

Keywords: transition; practice; graduate; student; occupational therapy

\section{Introduction}

Occupational therapy programs aim to prepare graduates for competent practice; however, current research indicates that graduates frequently feel unprepared and often lack confidence in their knowledge and skills [1]. In an online survey of 178 Australian and 53 New Zealand occupational therapy graduates, only $17.1 \%$ of Australian students and $8.5 \%$ of New Zealand students stated they felt prepared to enter the workplace on graduation. The majority of the respondents (66.4\%) reported feeling only somewhat prepared, and a further $10.3 \%$ reported feeling somewhat unprepared or not prepared at all [2].

Successful transition to practice is crucial to becoming a competent clinician. Development of competence requires education, experience, and supervision. Through these processes, a student learns to integrate practical knowledge and clinical reasoning [1]. The transition period typically spans from a student's final academic year to the end of his/her first year of practice. This period has been identified as a challenging and stressful time and often involves the re-defining of the self through a process of intense professional and personal growth [1-4]. The tension of translating classroom education to the working environment is particularly evident during this period and issues that may arise include a lack of role clarity, a perception of insufficient supervision, and a lack of confidence in professional skills $[3,4]$.

There is limited discussion in the literature of specific strategies that may be employed to assist graduates in their transition to practice [1-4]. The purpose of this paper is to raise awareness of occupational therapy graduates' need for support through this transition period, and to describe 
an example of a job-seeking support initiative, introduced by an Australian occupational therapy program, which may have merit for the transition process, and warrant research.

\section{Background}

Studies indicate that students have an expectation that they will feel competent and valued as they transition to the role of occupational therapist, however, there is frequently a disconnect between a new graduate's expectations and the realities of their experience [2,5]. Prior to entering the workforce, new graduate occupational therapists report having high expectations regarding workplace culture, role demands, professional development and job satisfaction [4-7]. A longitudinal study of 295 Australian occupational therapy graduates found the most important factors in successful transition to practitioner were a sense of job satisfaction and realization of expectations that were held prior to graduating. Interestingly, these factors also influenced whether they chose to continue working within the occupational therapy profession [6]. Results indicated that unmet expectations can lead to a phenomenon that the researchers termed 'Reality Shock', an experience characterized by feelings of stress, conflict, role uncertainty and withdrawal [6]. Further studies support this concept, also finding that recently graduated occupational therapists often experience difficulties in the early years of working. These difficulties, in part, being attributed to a gap between expectations of practice as an occupational therapist and the actual experience [1,2].

Employers also have expectations, but importantly, these expectations should not conflict with those of the new graduate. Employers of occupational therapists seek a range of qualities from staff, most frequently placing importance on experience, ability and skills to work within a team, skills in the field of practice, and communication and interpersonal skills [8]. However, studies also show that employers recognize that recent graduates will typically have less experience and skills than therapists who have worked for many years [8], and occupational therapists' employers accommodate this by modifying their expectations, both when hiring staff, and in the actual workplace. Employers, instead, place emphasis on the range of abilities and attitudes that demonstrate potential in a new graduate, in particular, enthusiasm, willingness to learn, independence and proactive help-seeking [8]. Unfortunately, it is not clear whether employers convey to new graduates the importance they place upon these qualities, or that they are cognizant of the need to modify their expectations. A lack of clear communication about these expectations from both the employer and the new graduate may further increase the tension of the transition period for new graduates.

Studies of recent graduates have also found a number of common themes relating to their experiences in the workforce. A qualitative study, focusing on six Canadian occupational therapy graduates, showed that participants perceived a gap between skills taught in the classroom and skills required for practice [9], and described a range of common concerns including limited practical experience, responsibility for client care, role uncertainty, and feelings of doubt and apprehension regarding their performance. When commencing practice, the graduates struggled with understanding their role, were unsure of the processes for learning new clinical skills and struggled working within teams [9]. Similar concerns have also been identified by graduates in other countries. A focus group of occupational therapy graduates from a New Zealand university aimed to identify the challenges they experienced during their transition to practice. Participants reported concerns that included insufficient support from supervisors, a feeling of having limited knowledge and clinical competence, inadequate communication skills and insufficient skills for working with teams and diverse populations [7]. Results from comparable studies looking at Australian and British occupational therapy graduates show similar findings [3-5]. The issues most frequently identified in these studies were concern regarding role clarity, perceived insufficient supervision and a lack of confidence. Lack of confidence was found to be particularly related to the graduates' clinical skills and their belief in their ability to apply these skills [3-5]. Other concerns identified included the need to do clerical work, staff hierarchy, and feeling shocked by unexpected revelations, which included the assumption that practice would 
be less stressful than student life [3,4]. These studies also provide support for the concept of 'Reality Shock' and underline the need to find ways to support graduates through this transition period [6].

The process of transition from student to practitioner also involves the development of professional skills and professional identity. Professional identity, in particular, has been found to affect overall job satisfaction which, in turn, impacts on the retention of therapists within the occupational therapy profession [10]. A study of seventy-four occupational therapists from the United Kingdom found that many new graduates place an emphasis on profession-specific supervision as a means of building their professional skills and identity [11]. Training and development activities available to occupational therapists within the workplace may include professional and informal supervision, support groups, continuing professional development schedules and journal clubs. Programs may also include regular feedback, role clarity and shared reflection sessions [11]. This research reported that two-fifths of the time graduates spent with their professional supervisor was focused on clinical casework, with the remaining time being divided between professional development and support. Graduates participating in this study wanted more time spent on professional development $(60 \%$ of respondents), more emphasis to be placed on clinical casework (33\%), and greater time spent on support (22\%). Furthermore, although $98 \%$ of participants had access to regular clinical supervision, access to mentorship or preceptorship with an experienced occupational therapist was reported as minimal [11].

Although evidence is limited, mentorship or preceptorship programs for graduates' transition to practice have been reported to facilitate the development of clinical skills and professional behavior. A 2005 British study collected qualitative data from four occupational therapy graduates and six supervisors participating in a transition to practice program. The program consisted of sessions of observed practice and was followed by a shared reflection [4]. Structured inductions to assist with role clarity, role modeling, discussion of team culture, supervision, and preceptorship were all support strategies used by the supervisors. According to these results, new occupational therapy graduates rated supervision and preceptorship as highly valuable and, without access to these supports, graduates felt constrained in their development [4]. Perceived lack of a mentor or role model is problematic for new graduates' development of their self-image as an occupational therapist, and this may contribute to role confusion.

Role confusion is a frequently identified issue occurring during the process of transition to practitioner [3,4]. Supervision not only provides the opportunity to receive feedback but also provides a role model for the new graduate. The perceived shortfall of supervision may be due to a relative lack of structure in some workplaces. A barrier to access to sufficient high quality professional supervision for new graduates may be the need to seek out their own feedback or supervision, and to develop a process through which this can occur [6]. In addition, shortage of staff and resources could also play a role in the perceived lack of professional supervision.

Researchers have sought to determine what interventions support transition. Studies have found that these include supervision, access to role models and feedback from colleagues and supervisors. In particular, supervision and feedback are suggested to be essential components in facilitating the transition from student to practitioner and has been rated by new occupational therapy graduates as the most useful tool to their development in the workplace $[6,10,12]$. Graduates who had fewer opportunities for supervision and feedback reported being less confident in their abilities, more reluctant to seek advice, and feeling they had a more stressful transition overall. Feedback on performance influences self-perception of confidence and competency, and new occupational therapy graduates who did not receive feedback reported feelings of self-doubt [13,14].

The importance of supervision from an experienced therapist in the same profession should not be underestimated; supervision is important in assisting new graduates as they build confidence and profession specific skills, and very importantly, for the development of professional identity [5]. A study of one hundred and fifty-one New Zealand and Australian occupational therapy graduates found that $96 \%$ of new graduates who received supervision reported that it facilitated their development of clinical 
skills, enhanced the quality of service to clients, and clarified their role as an occupational therapist. Additionally, it has been frequently reported that new graduates often expect supervisors to provide specific and regular support but are often dissatisfied with the amount of supervision provided [15]. Studies show that graduates reported wanting more support, in the form of preceptorship and supervision, than was readily available [5-7].

The demands placed on new graduate occupational therapists are increasing, traditional work settings with easy access to peer support and profession-specific mentorship are less common, and the need for clinical competence and practitioners with strong professional identities is critical [8]. The stresses and challenges experienced by students as they transition to practitioner are areas that need to be addressed in the workplace, the classroom and in the wider professional community. Professional identity is an important precursor to undertaking the complex tasks required when entering the workplace. The development of professional identity is complex and requires a dynamic blend of practice experience, supervision, confidence-building and feedback $[4,7]$.

While structured programs to support new graduates are commonly seen in nursing and medicine, there has been little published on similar initiatives within the allied health professions [7]. A study by Smith and Pilling in 2008 [7] describes a strategy to support new graduate therapists during their transition to employment. The program was open to a mix of disciplines including occupational therapy, physiotherapy and speech pathology. There were approximately eleven to thirteen graduates participating each year. The program consisted of eight interactive sessions, lasting two hours and held over a twelve month period. The objective of the interactive sessions was to support new graduates by providing role clarity, promoting interdisciplinary collaboration and encouraging critical reflection skills [7]. Evaluation of the program involved feedback from participants over a three-year period. Identified strengths and benefits of the sessions included the multi-professional support they provided, reduction of feelings of isolation, informal feedback, teaching and debriefing, and opportunities for reflection. Areas of the program the participants felt could improve included reducing follow-up tasks between sessions, increased program enrolment numbers, and a greater balance between structured activity and open opportunity to debrief. Many of the participants reported more confidence in the workplace after five to six months of participation in the program. This finding was particularly relevant for the graduates who were in their first year of practice, and supports the need for this type of program to be available for recent graduates. However, feedback also showed as participants spent more time in the workforce they correspondingly reported they found the program became less useful to them [7]. This additional finding suggests transition to employment programs may be important for graduates during the first six to twelve months after finishing their degree, however, after this time the majority of graduates no longer feel the need for support.

Studies within educational research have recommended a number of processes to support the transition from student to practitioner. These processes include bridging academic settings to clinical settings through increased fieldwork opportunities, formal entry to practice units incorporated into occupational therapy university courses and support programs for new graduates. Support may be provided via preceptorship, effective professional and informal supervision, continuing professional development schedules, regular feedback opportunities and specific transition to practice support programs. The combination of these strategies has been shown to facilitate successful transition to practice for occupational therapy graduates $[3,7,11]$.

In summary, research shows that the most frequent issues and challenges identified by new graduate occupational therapists include a perceived lack of clinical skills and a lack of supervision/mentoring in the workplace that also includes a focus on professional development. These factors contributed to low confidence, role uncertainty, and poor professional and personal development [5]. New graduate occupational therapists arrive at the workplace with high expectations; however, these expectations, if unmet, result in stress, feelings of incompetence, and withdrawal [16]. While students reported overall satisfaction with their preparedness in terms of theoretical knowledge, the contextualization of this knowledge is often difficult [9]. The large gap between what new graduates 
expect from supervision in the workplace and what they actually receive is another common concern. New occupational therapy graduates are looking to consolidate their skills, feel confident in their role, and have access to professional supervision. A growing body of research also identifies that students who are transitioning to therapists require supervision and support to help them achieve their learning goals, understand their complex role, and increase their confidence and competency in the workplace [16].

However, it can be argued that strategies to support the transition to practice of new graduates is not the exclusive responsibility of the employer, but is a responsibility to be shared among all stakeholders. These stakeholders include occupational therapy professional associations, national registration boards and universities. This following section of this paper briefly describes a university initiative to address the transition to practice of its new graduate occupational therapists.

\section{Case Study: Job Club}

\subsection{Formation}

The four-year undergraduate degree in occupational therapy at Edith Cowan University has a strong focus on graduates' readiness for practice. A number of initiatives and teaching strategies within the program aim to prepare students for their transition from student to therapist. These strategies include a 'Preparation for Work' seminar day held each year for graduating students. It was at the 2014 'Preparation for Work' seminar, that faculty recognized significant anxiety among graduating students in relation to their employment prospects. This anxiety was occurring within the context of a changing job market in Western Australia. The number of occupational therapy jobs was limited, as a result of a government freeze on recruitment, restructure of existing services and a nationally recognized oversupply of occupational therapy graduates, which presented a greater challenge for new graduates in particular. In response to this situation Edith Cowan University faculty proposed forming the 'Occupational Therapy Job Club'.

Initially, it was proposed that the Job Club format focus on advice and support specifically related to the job-seeking process. This included instruction on how to respond to job application selection criteria, and opportunities to explore interview situations via role-play and discussion. A key aim of the club was the opportunity for graduates to share networking strategies and job seeking experiences. Over time, however, the initiative began to evolve, as a result of needs, expressed by the graduates, for support in the complex process of transitioning from student to practitioner.

The Job Club commenced in 2015 with bimonthly meetings. Job applications and interview preparation were the focus of the first three sessions, after which graduates began to propose their own topics. Through this process, the focus of the group shifted to the expressed needs of the graduates, with an emphasis on addressing the issues that they considered most important, for example, assistance in understanding the local continuing professional development requirements. To address this need, the Job Club facilitators organized a webinar with representatives from the local occupational therapy association. Meetings took on an informal small group style, which encouraged graduates to share their job seeking experiences, and allowed discussion to move into topics of greatest importance to the graduates. The inaugural Job Club continued until all graduates found employment, however, it was decided that a limited term arrangement would be better in subsequent years.

\subsection{Current Format}

The scope of the club has expanded and Job Club is now open to all occupational therapy graduates from the preceding year, regardless of whether they are still seeking employment, are employed in full-time or part-time occupational therapy positions, or are working in non-occupational therapy roles whilst seeking more profession-specific work.

During the first year of Job Club, graduates raised concerns about their opportunities to consolidate skills and develop confidence, while having limited experience and also minimal 
supervision. Due to the restructure of services, some graduates were employed under the supervision of non-occupational therapy professionals. For some, with limited access to occupational therapy mentors, role models, and engagement in the culture of occupational therapy, the process of defining themselves as 'occupational therapists', rather than 'students', was at risk of occurring within a professional vacuum. Graduates employed in non-occupational therapy positions, and those who were not yet employed, appeared to be experiencing apprehension and uncertainty about their development as occupational therapists. Several graduates with supervisors from other professions expressed concern that they would be unable to receive the discipline-specific guidance they had come to expect from senior occupational therapy faculty during their undergraduate fieldwork placements. Job Club provided an avenue to express and process these concerns.

Opportunities for reflection also evolved from the employment stories that graduates shared during the sessions. In one instance, a graduate was unable to attend the Job Club session because she was working long hours. The graduate's peers passed on her concerns about workplace processes and expectations. They were worried that their friend was finding the new position stressful, and were concerned their friend did not have the opportunity for discipline-specific supervision or avenues to discuss her experiences. At subsequent meetings, the Job Club facilitators, both practitioners as well as academics, were able to offer the graduate an opportunity to discuss and process her experiences. This enabled her to build confidence in clinical reasoning and problem-solving and develop strategies to address her learning needs.

Job Club has evolved; it has also become a valuable two-way communication between the university and graduates. Information from the faculty about professional development opportunities, casual employment offers from the professional field, and occupational therapy interest group meetings have been well-received by club members. Graduates involved with Job Club have also become an enthusiastic pool of university volunteers, who are eager to assist with tasks such as Open Day and First Year Orientation. There has also been an opportunity to engage interested graduates in voluntary work at the university paediatric and neurology occupational therapy clinics. This has allowed the clinics to expand and offer valuable services to an increased number of people within the community.

Additionally, as a result of networking discussions held during Job Club, a number of graduates have commenced in volunteer roles within a range of occupational therapy services in the community. These graduates are willing and eager to work on a voluntary basis alongside experienced clinicians. In turn, the clinicians are able to help the graduates to develop a strong professional identity. They are supported to redefine and validate themselves as professional occupational therapists during the difficult transition period between graduating and leaving their student role behind and securing an occupational therapy position.

\subsection{Member Feedback}

Faculty observed that the Job Club was becoming a valuable opportunity for graduates to reflect on their employment or pre-employment experiences; process expectations and feelings; foster confidence and build connections with their profession. This was also reflected in feedback from attendees obtained via a quality improvement activity. Comments included "I found, whilst it was useful for tips, hints and information, the main benefit [of Job Club] was the support and catching up with other new grads and hearing about their experiences, whether job hunting or working", "I liked feeling included and having that network still open after uni", and "it is very helpful especially sharing struggles with peers [whilst receiving] support from lecturers". The quality improvement survey also showed that all graduates saw Job Club as a good way to catch up with peers, get support in relation to job seeking and to ease the transition from graduate to occupational therapist.

\section{Conclusions}

Increasing the scale and capacity of rehabilitation services to manage the extensive and growing unmet need is a global healthcare priority [17]. This is no small task and much research is required 
to address the "increasingly complex global landscape of occupational therapy practice along with growing evidence that graduates were not sufficiently prepared for the challenges of an uncertain world" [18]. With this in mind, all stakeholders need to understand that it is no longer sufficient to simply educate and hire therapists. We must think more broadly and address the issues related to maximizing occupational therapists', and indeed all rehabilitation therapists', capacity as they enter the healthcare field. An additional contemporary reality being that the education of an occupational therapist comes at a significant cost to the individual, their family and society in general. Successful transition to the workplace promotes job satisfaction and reduces attrition. This may mean that initiatives such as Job Club could reduce the risk of losing new graduates from the profession. Future exploration around this would be worthwhile. While research on transition to work is still limited in the area of rehabilitation, there is a significant body of study we can draw on from the field of nursing. In nursing, new graduate mentorship, confidence building, and fostering of a sense of contribution and impact on others' well-being have been determined to be key strategies to increase engagement and mastery. These strategies are also effective at decreasing burnout and attrition [19].

As educators and academics, our perspective is that support for transition to employment is essential. Essential work, however, does not have to be complicated nor resource intensive. Job Club requires modest input, it is significantly facilitated by the graduates themselves, and perhaps most importantly, it avoids a highly formalized process. As a consequence, the club has the ability to be nimble in responding to graduates' changing context, needs and aspirations.

A future, longitudinal study of the Job Club concept will be helpful to understand the role that universities could play in supporting the transition process for graduates. With a changing employment landscape for occupational therapy graduates in Australia; this is an important discussion that needs to be on the radar for academics. However, the authors recognize the limitations to this paper, including the need for formal research on this initiative, and the contexts in which it can operate effectively.

Author Contributions: All authors participated in manuscript writing and revision. Additionally, Katrina Liddiard and Rachel Batten provided insights specific to Job Club and Yuluan Wang carried out the literature search.

Conflicts of Interest: The authors declare no conflict of interest.

\section{References}

1. Seah, C.A.; Mackenzie, L.; Gamble, J. Transition of graduates of the master of occupational therapy to practice. Aust. Occup. Ther. J. 2011, 58, 103-110. [CrossRef] [PubMed]

2. Gray, M.; Clack, M.; Penman, M.; Smith, J.; Bell, J.; Thomas, Y.; Trevan-Hawke, J. New graduate occupational therapists feelings of preparedness for practice in Australia and Aotearoa/New Zealand. Aust. Occup. Ther. J. 2012, 59, 445-455. [CrossRef] [PubMed]

3. Morley, M. Contextual factors that have an impact on the transitional experience of newly qualified occupational therapists. Br. J. Occup. Ther. 2009, 72, 507-514. [CrossRef]

4. McCombie, R.P.; Antanavage, M.E. Transitioning from occupational therapy student to practicing occupational therapist: First year of employment. Occup. Ther. Health Care 2017, 31, 126-142. [CrossRef] [PubMed]

5. Robertson, L.J.; Griffiths, S. Graduates' reflections on their preparation for practice. Br. J. Occup. Ther. 2009, 72, 125-132. [CrossRef]

6. Sutton, G.; Griffin, M.A. Transition from student to practitioner: The role of expectations, values and personality. Br. J. Occup. Ther. 2000, 63, 380-388. [CrossRef]

7. Smith, R.; Pilling, S. Supporting the transition from student to professional-A case study in allied health. Aust. Health Rev. 2008, 32, 134-138. [CrossRef] [PubMed]

8. Mulholland, S.; Derdall, M. Exploring what employers seek when hiring occupational therapists. Can J. Occup. Ther. 2004, 71, 223-229. [CrossRef] [PubMed]

9. Toal-Sullivan, D. New graduates' experiences of learning to practise occupational therapy. Br. J. Occup. Ther. 2006, 69, 513-524. [CrossRef] 
10. Hodgetts, S.; Hollis, V.; Triska, O.; Dennis, S.; Madill, H.; Taylor, E. Occupational therapy students' and graduates' satisfaction with professional education and preparedness for practice. Can J. Occup. Ther. 2007, 74, 148-160. [CrossRef] [PubMed]

11. Morley, M.; Rugg, S.; Drew, J. Before preceptorship: New occupational therapists' expectations of practice and experience of supervision. Br. J. Occup. Ther. 2007, 70, 243-253. [CrossRef]

12. Doherty, G.; Stagnitti, K.; Schoo, A.M. From student to therapist: Follow up of a cohort of Bachelor of Occupational Therapy students. Aust. Occup. Ther. J. 2009, 56, 341-349. [CrossRef] [PubMed]

13. Morley, M. Moving from student to new practitioner: The transitional experience. Br. J. Occup. Ther. 2006, 69, 231-233. [CrossRef]

14. Tryssenaar, J.; Perkins, J. From student to therapist: Exploring the first year of practice. Am. J. Occup. Ther. 2001, 55, 19-27. [CrossRef] [PubMed]

15. Sutton, G.; Griffin, M.A. Integrating expectations, experiences, and psychological contract violations: A longitudinal study of new professionals. J. Occup. Organ. Psychol. 2004, 77, 493-514. [CrossRef]

16. Fitzgerald, C.; Moores, A.; Coleman, A.; Fleming, J. Supporting new graduate professional development: A clinical learning framework. Aust. Occup. Ther. J. 2015, 63, 13-20. [CrossRef] [PubMed]

17. World Health Organization. Rehabilitation 2030: Key for Health in the 21st Century. 2017. Available online: http:/ / www.who.int/disabilities / care/KeyForHealth21stCentury.pdf?ua=1 (accessed on 28 February 2017).

18. Wimpenny, K.; Lewis, L.; Roe, S.; Désiron, H.; Gordon, I.; Waters, S. Preparation for an uncertain world: International curriculum development for mental health occupational therapy. World Fed. Occup. Ther. Bull. 2016, 72, 5-15. [CrossRef]

19. Laschinger, H.K.S. Job and career satisfaction and turnover intentions of newly graduated nurses. J. Nurs. Manag. 2012, 20, 472-484. [CrossRef] [PubMed]

(C) 2017 by the authors. Licensee MDPI, Basel, Switzerland. This article is an open access article distributed under the terms and conditions of the Creative Commons Attribution (CC BY) license (http://creativecommons.org/licenses/by/4.0/). 